\title{
Changes in Bacterial Composition of Zucchini Flowers Exposed to Refrigeration Temperatures
}

\author{
F. Baruzzi, M. Cefola, A. Carito, S. Vanadia, and N. Calabrese \\ Institute of Sciences of Food Production, National Research Council of Italy (CNR-ISPA), Via. G. Amendola 122/o, 70126 Bari, Italy \\ Correspondence should be addressed to F. Baruzzi, federico.baruzzi@ispa.cnr.it
}

Received 20 October 2011; Accepted 8 December 2011

Academic Editor: Mario Vaneechoutte

Copyright () 2012 F. Baruzzi et al. This is an open access article distributed under the Creative Commons Attribution License, which permits unrestricted use, distribution, and reproduction in any medium, provided the original work is properly cited.

Microbial spoilage is one of the main factors affecting the quality of fresh fruits and vegetables, leading to off-flavor, fermented aroma, and tissue decay. The knowledge of microbial growth kinetics is essential for estimating a correct risk assessment associated with consuming raw vegetables and better managing the development of spoilage microorganisms. This study shows, for the first time, that only a part of total microbial community, originally present on fresh harvested female zucchini flowers, was able to adapt itself to refrigerated conditions. Through the study of microbial growth kinetics it was possibleto isolate forty-four strains belonging to twenty-two species of the genera Acinetobacter, Arthrobacter, Bacillus, Enterobacter, Erwinia, Klebsiella, Pantoea, Pseudoclavibacter, Pseudomonas, Serratia, Staphylococcus, and Weissella, suggesting Enterobacteriaceae as potentially responsible for pistil spoilage.

\section{Introduction}

The fresh-like and healthy traits of ready-to-use (RTU) products such as leafy vegetables (lettuce, rocket, spinach, etc.) and fruits (melon, pineapple, apricot, peach, apple, etc.), with a minimal time of preparation before consumption, are characteristics sought by consumers [1-3]. Microflora causing release of off-flavors and tissue decay is well known in both RTU vegetables and fruits [4-9]. The dominating bacterial population during low temperature storage mainly consists of species belonging to the Pseudomonadaceae and Enterobacteriaceae; besides some species belonging to the lactic acid bacteria and moulds may be present at relatively lower numbers $[4,10-13]$.

The consumption of zucchini (Cucurbita pepo L.) flowers with the immature fruit attached is spread in many countries, specially in the Mediterranean area, but, due to their high perishability, they are in general marketed only locally.

Different authors $[14,15]$ studied the effects of cold storage on zucchini flowers processed as a new RTU vegetable; these papers showed that the shelf life of flowers was affected either by low storage temperatures and by cultivars. However, no study is reported in literature on the evolution under refrigerated conditions of natural microbial population occurring on female zucchini flowers that, composed by petals and pistil, presents different tissues and nutrient availabilities.

Aim of this work was to gain a better knowledge about the survival of natural microorganisms occurring on female zucchini flowers, potentially involved in vegetable spoilage, in order to lay the basis for the development of a new RTU vegetable.

\section{Materials and Methods}

2.1. Microbiological Analyses of Zucchini Flowers. Microbial evaluation on growth kinetics in zucchini female flowers (cv. Aquilone) was carried out in two consecutive years (trial A and B). Clean flowers, with their immature fruit attached, were harvested and immediately subjected to microbiological analyses.

At the same time, zucchini flowers were stored, as harvested, in gas permeable polypropylene open bags at $4^{\circ} \mathrm{C} \pm$ $1^{\circ} \mathrm{C}$ for 11 days. Three replicate bags of eight zucchini flowers were prepared for each sampling time (4, 8, and 11 days).

Microbial analysis was carried out on about $25 \mathrm{~g}$ of petals and pistils transferred aseptically and separately to 
a stomacher bag, containing 9 parts $(w / w)$ of sterile saline solution $(0.9 \% \mathrm{NaCl})$ and homogenized for 1 min using a stomacher (BagMixer, Interscience, St Nom, France). Petal and pistil dilutions were plated in triplicate on different agar media. Total mesophilic bacteria (Plate Count Agar, Oxoid S.p.A. Garbagnate, Milano, Italy) and Enterobacteriaceae (Violet Red Bile Glucose Agar) were counted after $24 \mathrm{~h}$ of growth at $30^{\circ} \mathrm{C}$, yeasts and moulds (Potato Dextrose Agar) at $25^{\circ} \mathrm{C}$ for four days, whereas presumptive lactic acid bacteria (Rogosa agar under anaerobiosis) were enumerated after $48 \mathrm{~h}$ of growth at $30^{\circ} \mathrm{C}$. In order to prevent yeast growth, $150 \mathrm{mg} \mathrm{L}^{-1}$ of cycloheximide were added to Rogosa and PCA, while to prevent bacterial growth $150 \mathrm{mg} \mathrm{L}^{-1}$ of chloramphenicol were added to PDA. Microbial biotyping and species identification were carried out on isolates from the dominant bacterial population.

For each storage time $(0,4,8$, and 11 days), about 10 15 well-isolated colonies were picked up from PCA plates with the highest number of colonies, inoculated in PC broth (Tryptone $5.0 \mathrm{~g} \mathrm{~L}^{-1}$, Yeast extract 2.5 , Glucose $1.0 \mathrm{~g} \mathrm{~L}^{-1}$, Oxoid S.p.A. Garbagnate, Milano, Italy), incubated at $30^{\circ} \mathrm{C}$ for $24 \mathrm{~h}$ and frozen at $-80^{\circ} \mathrm{C}$ for further analyses.

2.2. Microbial Biotyping and Species Identification. DNA extraction was carried out using one $\mathrm{mL}$ of viable cell suspension by using Wizard Genomic DNA Purification kit (Promega Italia Srl, Milano, Italy) following manufacture's instructions. DNA quantity and quality were determined by electrophoresis with known amounts of molecular weight marker (Marker IV, Roche Diagnostics, Milan, Italy) as a standard.

Isolates were submitted to the two-step RAPD analysis for biotyping [16] using the M13 primer ( $5^{\prime}$-GAGGGTGGCGGTTCT-3') capable of characterizing bacterial isolates from apples [17]. After electrophoresis run (2\% agarose in TBE buffer, QIAGEN, $70 \mathrm{~V}$ for 3-5 h), different isolates showing the same electrophoretic pattern were grouped. Isolates were clustered, sequenced, and identified as recently defined by Baruzzi et al. [18].

2.3. Evaluation of Spoilage Symptoms. Fruits and flowers were individually scored for spoilage symptoms (petal necrosis or water soaking, wilting, pistil acid rot, browning, and mycelia growth, etc.) by a group of six trained people using a 5 to 1 subjective scale, with $5=$ excellent, no spoilage; $4=$ very good, minor spoilage; 3 = fair, moderate spoilage; 2 = poor, major spoilage; $1=$ inedible. A score of 3 was considered as the limit of marketability and a score of 2 as the limit of edibility [19].

\section{Results and Discussion}

3.1. Enumeration of Different Microbial Populations Occurring on Zucchini Flowers. With the aim to identify the microorganisms, which could influence the spoilage, different microbial populations occurring on pistils and petals were evaluated.
Separating microbial counts by pistils or petals, pistil microbial load was always higher than the corresponding petal microbial population by about 1 or 2 logarithmic unit. The greatest differences in microbial populations were found for total mesophilic aerobic bacteria; in particular, for each sampling time and for both experiments, total mesophilic bacteria on pistils were found to be from 10 to 1000 times more than on petals. The differences between pistils and petals for Enterobacteriaceae and presumptive lactobacilli were far less marked. The nutrient availability on pistils can explain the higher microbial growth on pistils rather than on petals.

The growth kinetics of total aerobic bacteria, yeasts and moulds, presumptive lactobacilli, and Enterobacteriaceae on pistils during the storage at $4^{\circ} \mathrm{C}$ are shown in Figure 1. The viable cell counts of total aerobic bacteria, yeasts and moulds, and Enterobacteriaceae showed a similar behavior for both trials; after an initial reduction, microbial counts remained stable for some days and then increased after eight days in storage, reaching the highest value recorded for flowers in refrigerated conditions at the end of the experiment when spoilage symptoms were detected. In particular, viable cell counts of total aerobic bacteria (Figure 1) decreased from 10 (trial A) to 100 (trial B) times reaching about $6 \log \mathrm{cfu} \mathrm{g}^{-1}$ in both trials after eleven days of cold storage. The viable Enterobacteriaceae counts decreased from $1.0 \times 10^{5}$ to 2.4 $\times 10^{4} \mathrm{cfug} \mathrm{g}^{-1}$ in trial A and from $1.6 \times 10^{6}$ to $8.2 \times 10^{3}$ $\mathrm{cfug}^{-1}$ in trial B, increasing to about $5 \log \mathrm{cfu} \mathrm{g}^{-1}$ at the end of experiment for both trials. Total presumptive lactobacilli, usually known to be related to vegetable spoilage [10], showed counts (Figure 1) that remained relatively low, reaching $2.8 \times 10^{4} \mathrm{cfu}^{-1}$ only after eleven days of cold storage in trial B. Yeasts and moulds decreased 100 times in both trials with final values of $3.6 \times 10^{4} \mathrm{cfu} \mathrm{g}^{-1}$ and $5.6 \times$ $10^{2} \mathrm{cfu} \mathrm{g}^{-1}$ in trial A and B, respectively.

We can suppose that, after a selective effect of low temperatures on microflora counted on fresh female zucchini flowers, surviving microorganisms fitted well with the new cold environment, starting to grow. Microbial growth kinetics resulted similarly in both experiments; in particular, total aerobic counts resulted in the dominant microflora, followed by Enterobacteriaceae, whereas yeasts and moulds and presumptive lactobacilli remained stable or increased slowly.

Since total mesophilic aerobic bacterial population occurring in pistils was numerically dominant, it was considered, according to Ragaert et al. [2], responsible for female zucchini flower spoilage and then deeper investigated.

3.2. Microbial Biotyping and Taxonomic Identification. Biodiversity of aerobic mesophilic microflora from eight different pistil samples was studied analyzing RAPD-PCR profiles of 118 colonies from PCA plates. In general, every sample showed many different electrophoretic fingerprints, helping to identify the different strains present: clustering 118 colonies gave 44 strains. 16SrDNA analysis showed that in some cases different electrophoretic patterns belonged to the same species, confirming the ability of two-step RAPD analysis to differentiate isolates belonging to the same 


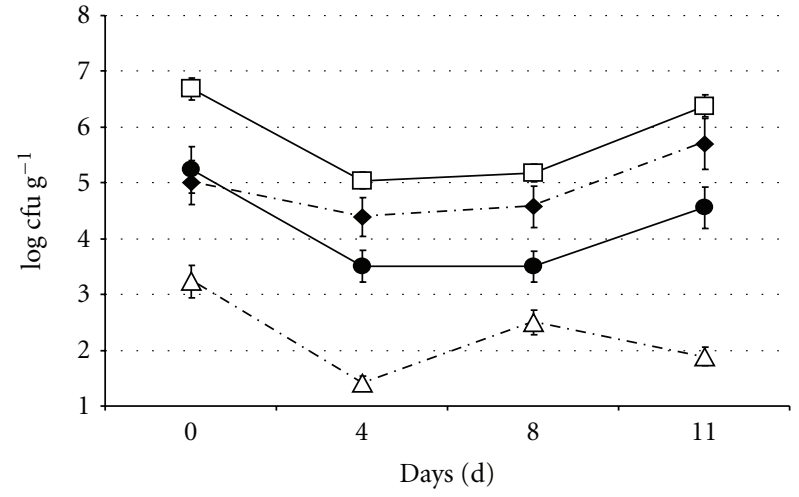

(a)

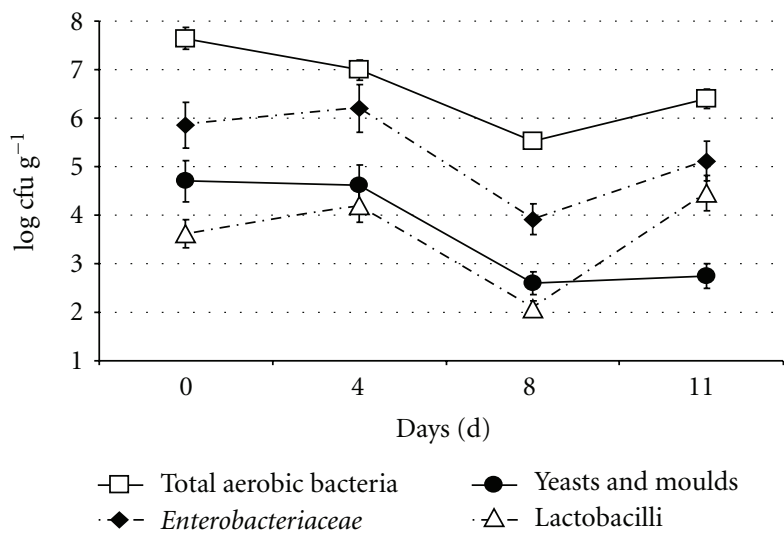

(b)

Figure 1: Growth dynamics of microbial populations from zucchini female flower pistils during cold storage at $4^{\circ} \mathrm{C}$ in trial A and $\mathrm{B}$. Mean value \pm standard deviation.

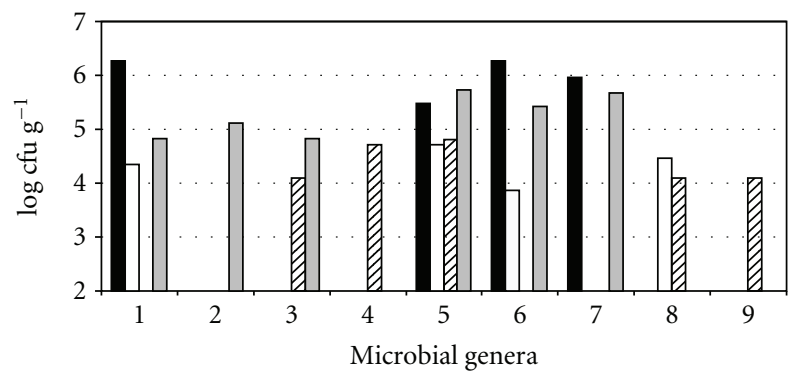

(a)

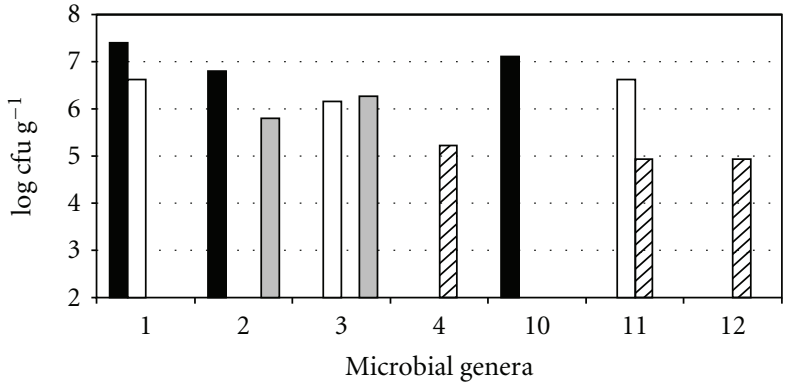

(b)

Figure 2: Distribution of bacterial genera and relative total load from zucchini female flower pistils in trial A and trial B after 0 (black bars), 4 (white bars), 8 (diagonal stripes bars), and 11 (grey bars) days of cold storage at $4^{\circ} \mathrm{C}$. Bacterial genera are defined as: 1 , Acinetobacter spp.; 2, Serratia spp.; 3, Klebsiella spp.; 4, Pantoea spp.; 5, Erwinia spp.; 6, Arthrobacter spp.; 7, Staphylococcus spp.; 8, Weissella spp.; 9, Pseudoclavibacter spp.; 10, Enterobacter spp.; 11, Pseudomonas spp.; 12, Bacillus spp.

species. The list of all strains isolated from pistils is presented in Table 1, whereas the distribution and the viable cell load of bacterial genera from pistils during trials $\mathrm{A}$ and $\mathrm{B}$ are shown in Figure 2. The cluster analysis carried out after RAPD-PCR and 16SrDNA analysis showed wide differences between trial A and B microflora. The trial A showed eight different fingerprints in naturally occurring bacteria on flowers, whereas isolates of trial B were clustered in four groups. During cold storage microbial isolates from trial A were grouped in six, eight, and fourteen RAPD-PCR cluster after four, eight, and eleven days of storage, respectively. The trial B was characterized by a lower level of microbial biodiversity showing six groups of isolates at any sampling time. The unstored flowers microflora was dominated by Acinetobacter sp. (Figure 2) in both trials, but the relative microbial load was higher in trial B. Together with this genus, after four days of storage other strains belonging to Weissella spp., Erwinia spp. and Arthrobacter spp. for trial A and Pseudomonas spp. and Klebsiella spp. for trial B appeared. After eight days, when the early damage symptoms became evident in zucchini flowers in the two experiments, other microbial genera were identified: Pantoea spp. in both trials, Erwinia spp., Pseudoclavibacter spp. and Weissella spp. in trial A or Pseudomonas spp. and Bacillus spp. isolated from trial B.

At the end of zucchini flowers cold storage, the dominant microflora in trial B were mainly Klebsiella and Serratia genera. In trial A, in addition to these genera, Staphylococcus spp., Acinetobacter spp., Arthrobacter spp., and Erwinia spp. were also detected. The microflora of both trials showed isolates belonging to Acinetobacter, Serratia, Klebsiella, and Pantoea genera. Isolates belonging to Erwinia spp. were always found in trial A and never in trial B, whereas, differently from trial A, no Staphylococcus strain was isolated from trial B samples.

Differences in microflora composition between trials could be also due to different environmental conditions during the growth of the zucchini flowers.

The strains isolated from both trials belonged to the following species: Acinetobacter calcoaceticus, Staphylococcus succinus and S. xylosus, Arthrobacter nicotianae, Serratia marcescens, Enterobacter aerogenes, Pantoea agglomerans, and Klebsiella oxytoca. The most frequently isolated species was 
TABle 1: List of strains identified from zucchini pistils harvested in Trial A and B at 0 (sample T0), 4 (sample T4), 8 (sample T8), and 11 (sample T11) days of cold storage.

\begin{tabular}{|c|c|c|c|c|c|}
\hline \multicolumn{3}{|c|}{ Trial A } & \multicolumn{3}{|c|}{ Trial B } \\
\hline Strain & Taxonomic identification & $\begin{array}{c}\text { Isolated in } \\
\text { sample }\end{array}$ & Strain & Taxonomic identification & $\begin{array}{c}\text { Isolated in } \\
\text { sample }\end{array}$ \\
\hline A5 & Acinetobacter calcoaceticus & T0 & C35 & Acinetobacter calcoaceticus & $\mathrm{T} 4$ \\
\hline A12 & Acinetobacter calcoaceticus & T0, T4 & C36 & Acinetobacter calcoaceticus & $\mathrm{T} 4$ \\
\hline A13 & Acinetobacter calcoaceticus & T0, T8, T11 & $\mathrm{C} 37$ & Acinetobacter calcoaceticus & $\mathrm{T} 4$ \\
\hline A83 & Acinetobacter sp. & $\mathrm{T} 11$ & C5 & Acinetobacter calcoaceticus & T0, T4, T8 \\
\hline A63 & Arthrobacter arilaiti & $\mathrm{T} 11$ & C3 & Acinetobacter sp. & T0 \\
\hline A16 & Arthrobacter nicotianae & T0 & C86 & Bacillus Megaterium & T8 \\
\hline A35 & Arthrobacter sp. & $\mathrm{T} 4$ & C107 & Enterobacter aerogenes & $\mathrm{T} 11$ \\
\hline A80 & Arthrobacter sp. & T0, T11 & $\mathrm{C} 20$ & Enterobacter aerogenes & T0 \\
\hline A81 & Arthrobacter sp. & T11 & $\mathrm{C} 74$ & Enterobacter sp. & T8 \\
\hline A9 & Erwinia persicina & T0, T4 & $\mathrm{C} 110$ & Klebsiella oxytoca & $\mathrm{T} 11$ \\
\hline A46 & Erwinia persicina & $\mathrm{T} 8, \mathrm{~T} 11$ & C38 & Klebsiella oxytoca & $\mathrm{T} 4, \mathrm{~T} 11$ \\
\hline A38 & Erwinia sp. & $\mathrm{T} 4$ & $\mathrm{C} 71$ & Pantoea agglomerans & T8 \\
\hline A64 & Erwinia sp. & $\mathrm{T} 8, \mathrm{~T} 11$ & C73 & Pantoea agglomerans & T8 \\
\hline A56 & Klebsiella oxytoca & T8 & C51 & Pseudomonas sp. & $\mathrm{T} 4, \mathrm{~T} 8$ \\
\hline A72 & Klebsiella sp. & $\mathrm{T} 11$ & $\mathrm{C} 122$ & Serratia marcescens & $\mathrm{T} 11$ \\
\hline A42 & Pantoea agglomerans & $\mathrm{T} 4$ & C19 & Serratia marcescens & T0 \\
\hline A57 & Pantoea agglomerans & T8 & & & \\
\hline A41 & Pantoea sp. & T8 & & & \\
\hline A 48 & Pseudoclavibacter helvolus & $\mathrm{T} 8$ & & & \\
\hline A77 & Serratia sp. & $\mathrm{T} 11$ & & & \\
\hline A82 & Serratia sp. & $\mathrm{T} 11$ & & & \\
\hline A65 & Staphylococcus saprophyticus & $\mathrm{T} 11$ & & & \\
\hline A17 & Staphylococcus succinus & T0, T11 & & & \\
\hline $\mathrm{A} 20$ & Staphylococcus succinus & T0 & & & \\
\hline A67 & Staphylococcus succinus & $\mathrm{T} 11$ & & & \\
\hline A62 & Staphylococcus xylosus & $\mathrm{T} 11$ & & & \\
\hline A26 & Weissella sp. & $\mathrm{T} 4$ & & & \\
\hline A53 & Weissella viridescens & $\mathrm{T} 8$ & & & \\
\hline
\end{tabular}

Acinetobacter calcoaceticus, present at each storing day in trial $\mathrm{A}$ and initially and after four and eight days in trial B.

Acinetobacter and Staphylococcus presented five strains; the remaining species showed one or two strains in both trials. As concerns strain growth kinetics, some strains ( $A$. calcoaceticus, E. persicina, S. marcescens, K. oxytoca, and $P$. agglomerans) were recovered in more than one sample. The species present at the highest concentrations were $A$. calcoaceticus and Staphylococcus succinus (trial A) and A. calcoaceticus, S. marcescens, and K. oxytoca (trial B) isolated from fresh flowers in which total aerobic load showed the highest values. The strains with the lowest microbial load were A. calcoaceticus and K. oxytoca found at the end of storage in trial A and Pseudomonas sp., Pantoea sp., Bacillus megaterium, and S. marcescens detected in trial B. Even when it was possible to identify the same strain in more than one sample, no single strain (or single species) was ever identified as being entirely responsible for the spoilage symptoms showed. The microbial isolates identified during the two trials were quite similar, having many common species. The identification of Pantoea agglomerans, Erwinia persicina, Serratia marcescens, and Enterobacter aerogenes in all samples confirms the importance of Enterobacteriaceae in microbial spoilage of cold stored vegetables, according to previous indications $[1,10,20]$.

A. baumannii and $A$. calcoaceticus form a phylogenetically complex of which only $A$. calcoaceticus is usually considered a nonpathogen soil-borne species [21]. We retained reliable the identification of Acinetobacter strains as belonging to A. calcoaceticus species, when the max score of alignment, calculated against sequences present in the Reference Sequence (RefSeq) database of other Acinetobacter species, was no higher than the $95 \%$ of that calculated for the top sequence match.

The microbial composition of zucchini flowers here reported partially resembles data from Janisiewicz and Buyer [22] relative to microflora associated with nectarine brown rot, that, in addition with strains belonging to other bacterial 
genus, reported the isolation of Enterobacter, Erwinia, Pantoea, Pseudomonas, Serratia, and Staphylococcus strains associated over a period of 7 weeks of nectarine development.

The microbial data showed many species and sometimes different strains of a single species (Table 1); since some strains were found both initially and at the end of cold storage, whereas other grew only during storage, it is possible to assume that only a part of total microbial community, originally present on flowers, was adaptable to refrigerated conditions.

The strain kinetic during cold storage highlighted the microbial biodiversity of flowers, underestimated in fresh flowers that usually are not subjected to severe changes in environmental conditions.

The Acinetobacter strains are often associated with food spoilage as previously demonstrated for meat, milk, and cheeses $[18,23,24]$.

The finding of some potentially pathogenic bacteriasuch as Acinetobacter spp. [25], K. oxytoca, Enterobacter aerogenes [26], and Serratia spp. [27, 28]-commonly found on vegetables, does not represent a risk for consumer health, since these vegetables are usually cooked before eating. Notably, in some cases (Erwinia persicina, Enterobacter aerogenes, Klebsiella oxytoca, and Serratia marcescens) the counts for single strains or species, from PCA plates, was significantly higher (more than 10 times) than Enterobacteriaceae counted on VRBGA plates. In addition, in both trials the shape of the Enterobacteriaceae growth curve appears the same, but with lower values, of total aerobic bacteria curve.

The results of this work seem to indicate that VRBGA is excessively selective for Enterobacteriaceae present on the flowers, leading us to underestimate this microbial load. The presence of $1.5 \mathrm{~g} \mathrm{~L}^{-1}$ of bile salts, needed to evaluate the coliforms present in milk and dairy products, could be selective against Enterobacteriaceae naturally occurring on vegetables where bile salts are absent. If similar results will be obtained for other vegetables, then the use of VRBGA for evaluating Enterobacteriaceae in these foods should be avoided.

3.3. Evaluation of Spoilage Symptoms. During both experiments (trial A and trial B), petals and pistils showed different types of spoilage. Generally, petals remained intact but their orange-yellow color lost natural brightness. In addition, petals turgidity reduction (score 3 or less) was observed after eleven days of refrigerated storage. Pistil spoilage occurred quickly just after eight days of cold storage, when about $80 \%$ of pistils appeared brown with gelatinous materials on the surface. Even though we did not perform assays direct to differentiate physiological from microbial spoilage, symptoms on petals remember physiological and biochemical tissue disorders caused by storage at low temperature for long time $[29,30]$, whereas pistil spoilage resembled soft rot caused by pectolytic and macerating enzymes of many plant pathogenic bacteria on different organs and succulent leaves of vegetables $[31,32]$. The evaluation of visual symptoms occurring on petals, pistils, and fruits of female zucchini flowers leads us to identify the pistils as the main perishable part limiting the marketability during the cold storage.

\section{Conclusions}

In this work we evaluated, for the first time, the microbial kinetics of natural occurring microflora of zucchini flowers developing under cold storage conditions; the most perishable part of female zucchini flower was represented by pistils, well known to have high amount of free simple sugars, in comparison with petals, with limited nutrient availability. Molecular tools enabled us to isolate forty-four strains from complex microflora developing on pistils suggesting Enterobacteriaceae as potentially responsible for pistil spoilage. However, due to the high microbial biodiversity found in all samples of both trials, the joint responsibility of other bacterial genera cannot be excluded.

A parallel result coming from data comparison from strain biotyping, taxonomic identification, and microbial isolation of different media is that the VRBGA media is excessively selective to evaluate Enterobacteriaceae from vegetables.

Microbial data from this work could be useful to set tools and technologies able to preserve the most delicate part of zucchini flower, the pistil, against spoiler microorganisms.

\section{References}

[1] I. Babic, S. Roy, A. E. Watada, and W. P. Wergin, "Changes in microbial populations on fresh cut spinach," International Journal of Food Microbiology, vol. 31, no. 1-3, pp. 107-119, 1996.

[2] P. Ragaert, F. Devlieghere, and J. Debevere, "Role of microbiological and physiological spoilage mechanisms during storage of minimally processed vegetables," Postharvest Biology and Technology, vol. 44, no. 3, pp. 185-194, 2007.

[3] D. Rico, A. B. Martín-Diana, J. M. Barat, and C. Barry-Ryan, "Extending and measuring the quality of fresh-cut fruit and vegetables: a review," Trends in Food Science \& Technology, vol. 18, no. 7, pp. 373-386, 2007.

[4] M. H. J. Bennik, W. Vorstman, E. J. Smid, and L. G. M. Gorris, "The influence of oxygen and carbon dioxide on the growth of prevalent Enterobacteriaceae and Pseudomonas species isolated from fresh and controlled-atmosphere-stored vegetables," Food Microbiology, vol. 15, no. 5, pp. 459-469, 1998.

[5] M. Giménez, C. Olarte, S. Sanz, C. Lomas, J. F. Echávarri, and F. Ayala, "Relation between spoilage and microbiological quality in minimally processed artichoke packaged with different films," Food Microbiology, vol. 20, no. 2, pp. 231-242, 2003.

[6] L. Jacxsens, F. Devlieghere, P. Ragaert, E. Vanneste, and J. Debevere, "Relation between microbiological quality, metabolite production and sensory quality of equilibrium modified atmosphere packaged fresh-cut produce," International Journal of Food Microbiology, vol. 83, no. 3, pp. 263-280, 2003.

[7] O. Lamikanra, K. L. Bett-Garber, D. A. Ingram, and M. A. Watson, "Use of mild heat pre-treatment for quality retention of fresh-cut cantaloupe melon," Journal of Food Science, vol. 70, no. 1, pp. C53-C57, 2005.

[8] M. A. Rojas-Graü, G. Oms-Oliu, R. Soliva-Fortuny, and O. Martín-Belloso, "The use of packaging techniques to maintain freshness in fresh-cut fruits and vegetables: a review," International Journal of Food Science \& Technology, vol. 44, no. 5, pp. 875-889, 2009.

[9] I. Vandekinderen, J. Van Camp, F. Devlieghere et al., "Effect of decontamination on the microbial load, the sensory quality and the nutrient retention of ready-to-eat white cabbage," 
European Food Research and Technology, vol. 229, no. 3, pp. 443-455, 2009.

[10] C. Nguyen-The and F. Carlin, "The microbiology of minimally processed fresh fruits and vegetables," Critical Reviews in Food Science and Nutrition, vol. 34, no. 4, pp. 371-401, 1994.

[11] K. Vankerschaver, F. Willocx, C. Smout, M. Hendrickx, and P. Tobback, "The influence of temperature and gas mixtures on the growth of the intrinsic micro-organisms on cut endive: predictive versus actual growth," Food Microbiology, vol. 13, no. 6, pp. 427-440, 1996.

[12] K. T. Rajkowski and X. Fan, "Microbial quality of fresh-cut iceberg lettuce washed in warm or cold water and irradiated in a modified atmosphere package," Journal of Food Safety, vol. 28, no. 2, pp. 248-260, 2008.

[13] M. Martínez-Ferrer and C. Harper, "Reduction in microbial growth and improvement of storage quality in fresh-cut pineapple after methyl jasmonate treatment," Journal of Food Quality, vol. 28, no. 1, pp. 3-12, 2005.

[14] A. M. Villalta, M. Ergun, A. D. Berry, N. Shaw, and S. A. Sargent, "Quality changes of yellow summer squash blossoms (Cucurbita pepo L.) during storage," Acta Horticulturae, vol. 659, pp. 831-834, 2004.

[15] N. Calabrese, F. Baruzzi, G. Signorella, and G. Damato, "Yield and microbial evaluation of summer squash pistillate flowers for "ready to use product". First results," Acta Horticulturae, vol. 741, pp. 221-227, 2007.

[16] F. Baruzzi, M. Morea, A. Matarante, and P. S. Cocconcelli, "Changes in the Lactobacillus community during Ricotta forte cheese natural fermentation," Journal of Applied Microbiology, vol. 89, no. 5, pp. 807-814, 2000.

[17] A. Ricelli, F. Baruzzi, M. Solfrizzo, M. Morea, and F. P. Fanizzi, "Biotransformation of patulin by Gluconobacter oxydans," Applied and Environmental Microbiology, vol. 73, no. 3, pp. 785792, 2007.

[18] F. Baruzzi, R. Lagonigro, L. Quintieri, L. Caputo, and M. Morea, "Occurrence of non-lactic acid microflora in high moisture cold stored Mozzarella cheese," Food Microbiology. In press.

[19] B. Pace, M. Cefola, F. Renna, and G. Attolico, "Relationship between visual appearance and browning as evaluated by image analysis and chemical traits in fresh-cut nectarines," Postharvest Biology and Technology, vol. 61, no. 2-3, pp. 178-183, 2011.

[20] E. Wevers, P. Moons, R. Van Houdt, I. Lurquin, A. Aertsen, and C. W. Michiels, "Quorum sensing and butanediol fermentation affect colonization and spoilage of carrot slices by Serratia plymuthica," International Journal of Food Microbiology, vol. 134, no. 1-2, pp. 63-69, 2009.

[21] H. C. Chang, Y. F. Wei, L. Dijkshoorn, M. Vaneechoutte, C. T. Tang, and T. C. Chang, "Species-level identification of isolates of the Acinetobacter calcoaceticus-Acinetobacter baumannii complex by sequence analysis of the 16S-23S rRNA gene spacer region," Journal of Clinical Microbiology, vol. 43, no. 4, pp. 1632-1639, 2005.

[22] W. J. Janisiewicz and J. S. Buyer, "Culturable bacterial microflora associated with nectarine fruit and their potential for control of brown rot," Canadian Journal of Microbiology, vol. 56, no. 6, pp. 480-486, 2010.

[23] M. Gennari, M. Parini, D. Volpon, and M. Serio, "Isolation and characterization by conventional methods and genetic transformation of Psychrobacter and Acinetobacter from fresh and spoiled meat, milk and cheese," International Journal of Food Microbiology, vol. 15, no. 1-2, pp. 61-75, 1992.
[24] P. Munsch-Alatossava and T. Alatossava, "Phenotypic characterization of raw milk-associated psychrotrophic bacteria," Microbiological Research, vol. 161, no. 4, pp. 334-346, 2006.

[25] L. Dortet, P. Legrand, C. J. Soussy, and V. Cattoir, "Bacterial identification, clinical significance, and antimicrobial susceptibilities of Acinetobacter ursingii and Acinetobacter schindleri, two frequently misidentified opportunistic pathogens," Journal of Clinical Microbiology, vol. 44, no. 12, pp. 4471-4478, 2006.

[26] Y. A. Markova, A. S. Romanenko, and A. V. Dukhanina, "Isolation of bacteria of the family Enterobacteriaceae from plant tissues," Microbiology, vol. 74, no. 5, pp. 575-578, 2005.

[27] V. Livrelli, C. De Champs, P. Di Martino, A. DarfeuilleMichaud, C. Forestier, and B. Joly, "Adhesive properties and antibiotic resistance of Klebsiella, Enterobacter, and Serratia clinical isolates involved in nosocomial infections," Journal of Clinical Microbiology, vol. 34, no. 8, pp. 1963-1969, 1996.

[28] A. B. Christensen, K. Riedel, L. Eberl et al., "Quorum-sensingdirected protein expression in Serratia proteamaculans B5a," Microbiology, vol. 149, no. 2, pp. 471-483, 2003.

[29] S. Chung, J. E. Staub, and G. Fazio, "Inheritance of chilling injury: a maternally inherited trait in cucumber," Journal of the American Society for Horticultural Science, vol. 128, no. 4, pp. 526-530, 2003.

[30] C. B. Watkins and J. H. Ekman, "Storage technologies: temperature interactions and effects on quality of horticultural products," Acta Horticulturae, vol. 682, pp. 1527-1533, 2005.

[31] C. B. Wegener, "Induction of defence responses against Erwinia soft rot by an endogenous pectate lyase in potatoes," Physiological and Molecular Plant Pathology, vol. 60, no. 2, pp. 91100, 2002.

[32] Y. Aysan, A. Karatas, and O. Cinar, "Biological control of bacterial stem rot caused by Erwinia chrysanthemi on tomato," Crop Protection, vol. 22, no. 6, pp. 807-811, 2003. 

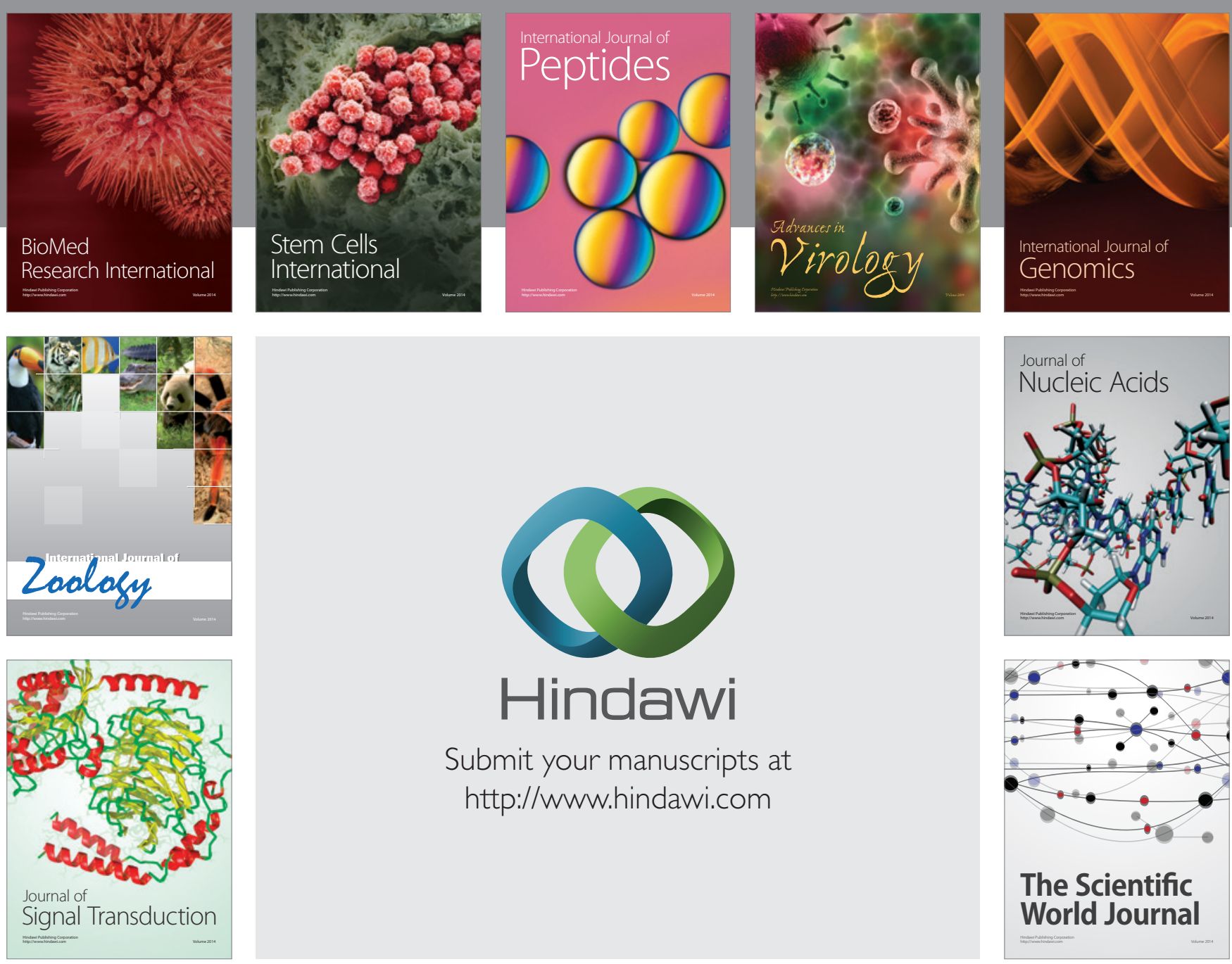

Submit your manuscripts at

http://www.hindawi.com
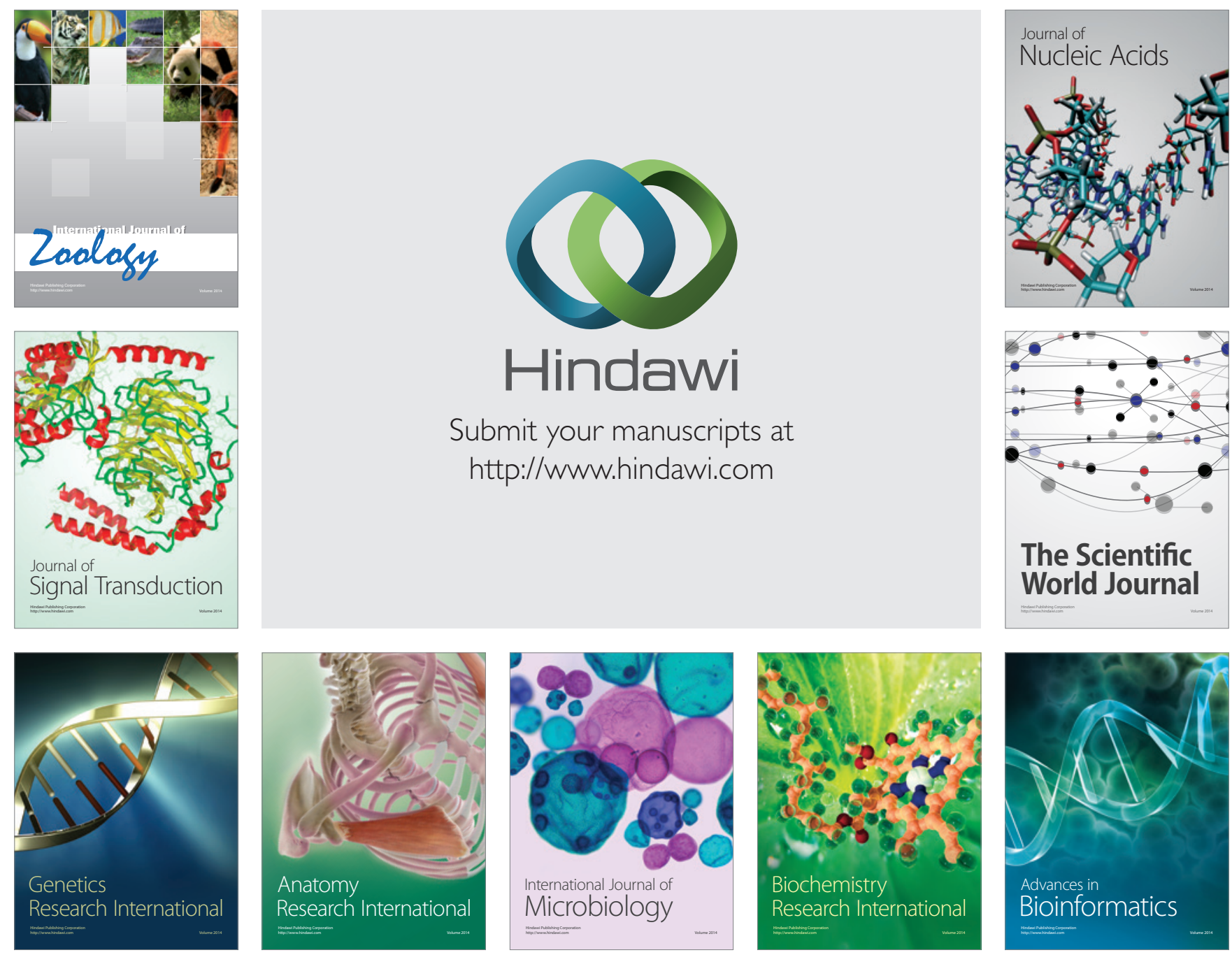

The Scientific World Journal
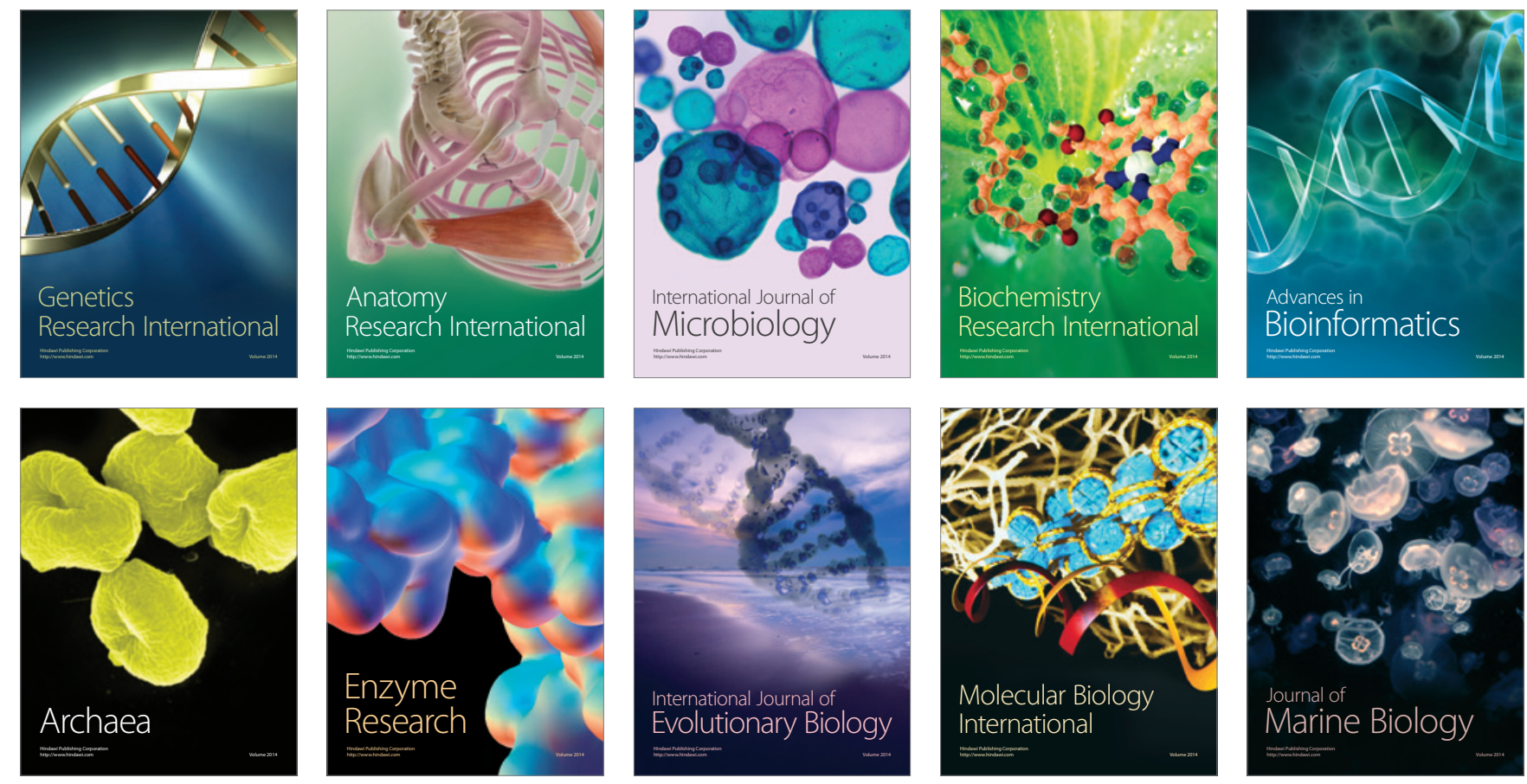